\title{
ESPIRITUALIDADE E VIDA COTIDIANA: A EXPERIÊNCIA DE TRANSCENDÊNCIA PELA FALA E PELA ESCUTA
}

\author{
[SPIRITUALITY AND EVERYDAY LIFE: THE EXPERIENCE OF TRANSCENDENCE THROUGH SPEECH \\ AND LISTENING]
}

Iraquitan de Oliveira Caminha * Universidade Federal da Paraíba, Brasil

\begin{abstract}
RESUMO: Este artigo discute a espiritualidade como caminho ou movimento para além de si, considerando a vida cotidiana a partir da experiência da fala e da escuta. Partimos da vida biológica no contexto das necessidades fundamentais associadas à sobrevivência. Em seguida, mostramos como o ser humano vai construindo, sob a base dessas necessidades, uma vida cultural que transcende a vida biológica sem, todavia, superá-la. Nossas reflexões têm como principal referência a filosofia de Merleau-Ponty, destacando a tensão entre o corpo como organismo da natureza e o corpo como obra de arte. Concluímos que a prosa, fruto da fala e da escuta, é fundamental para construirmos a espiritualidade na vida cotidiana.
\end{abstract}

Palangas-chaves: Espiritualidade; Transcendência; Vida Cotidiana; Fala. Escuta
ABSTRACT: This article discusses spirituality as a path or movement beyond oneself, considering everyday life from the experience of speech and listening. We start from biological life in the context of the fundamental needs associated with survival. Next, we show how the human being builds, on the basis of these needs, a cultural life that transcends biological life without, however, overcoming it. Our reflections have as main reference the philosophy of Merleau-Ponty, highlighting the tension between the body as an organism of nature and the body as a work of art. We conclude that prose, the fruit of speech and listening, is fundamental to build spirituality in everyday life.

KEYwORDS: Spirituality; Transcendence; Everyday life; Speech; Listening

\section{INTRODUÇÃo}

【samos a noção de espiritualidade nos termos proposto por Harari (2016) em seu texto Homo Deus: uma breve história do amanhã. Segundo ele, a espiritualidade é caminho, abertura. Noção diferente da religião, que nos remete às instituições e aos enquadramentos fechados dos espaços religiosos. Falamos de vida cotidiana fazendo referência ao dia-dia, a vida ordinária. Tomamos aqui o sentido de experiência como sendo aquilo que é da ordem de vivências subjetivas, próprias de cada sujeito. Concebemos a transcendência como sendo o dirigir-se para além de si, que manifesta o movimento de abertura para o outro, que resiste a toda forma de representação oclusa. Finalmente, a fala é a expressão própria de cada um por meio da estrutura de uma língua e a escuta é a atitude de um silêncio acolhedor, imprescindível para recepcionar a fala do outro.

* Professor do Departamento de Educação Física da Universidade Federal da Paraíba. E-mail: caminhairaquitan@gmail.com 
A religião, conforme Durkheim (1989), é um sistema solidário de crenças diretamente associado às coisas sagradas. Ela nos liga ao hierático por meio de uma comunidade moral que se estabelece como igreja. A experiência religiosa nos situa no âmbito da transcendência como manifestação de saída de si em busca do sagrado. Todavia, ela limita esta experiência aos enquadramentos rígidos das instituições religiosas em que as pessoas estão atreladas. A espiritualidade é abrir-se para o além sem estarmos acorrentados às amarras institucionais, que criam uma religiosidade emoldurada por exigências que, muitas vezes, impedem a experiência pessoal do sagrado. Desse modo, a espiritualidade como caminho nos exige retomar o tema da vida, sobretudo, a vida humana.

Compreendemos que a vida humana começa pelo corpo que é marcado pelas necessidades vitais que é da ordem da necessidade. Precisamos nos alimentar, respirar, excretar urina, fezes e suor. Essa é a nossa condição biológica. Mas não é nossa condição orgânica, considerada de maneira isolada e reduzida, que nos torna humano. É por essa razão que Merleau-Ponty (1992) afirma que o corpo humano é primordialmente obra de arte. Nesse sentido, ele tem uma dimensão expressiva que the faz sujeito de ações intencionais. Ele não se reduz às repetições mecânicas da vida funcional. Ele inventa e reinventa, cotidianamente, modos próprios de viver. O trabalho da natureza se estabelece por leis rígidas. O trabalho da cultura é feito pela plasticidade de vínculos socioafetivos que são flexíveis, fundamentalmente livres.

Merleau-Ponty (1992) nos ajuda a compreender que a natureza não está lá diante de nós como um objeto a ser explicado e dominado. Há uma relação de coabitação entre nosso corpo e a natureza. Pelo corpo, reconhecemos que nós habitamos a natureza e ela reside em nós. Somos seres naturais. Nesse mesmo caminho de compreensão da vida humana, podemos também encontrar na obra de Freud. Particularmente, podemos considerar sua obra $O$ Mal-estar na civilização. Nesse texto, é possível tomar a civilização como responsável pelo estabelecimento de formas de nos proteger dos ataques hostis da natureza e, ao mesmo tempo, regulamentar os vínculos dos humanos entre si (FREUD, 2010). Todavia, o esforço civilizatório não consegue eliminar o pendor natural à agressividade. Isso é a prova de que a natureza está sempre entrelaçada com a cultura.

Merleau-Ponty e Freud contribuem para superar a leitura positivista e determinista do corpo humano como estrutura meramente biológica. Segundo Caminha (2016), as noções de corpo próprio de Merleau-Ponty e de corpo pulsional de Freud são indispensáveis para considerar o corpo para além da vida natural. Nesse sentido, o corpo é capaz de realizar atos intencionais e pulsionais de ligar-se aos objetos que não são guiados por meras forças naturais. A intenção e o desejo determinam também nossos comportamentos. Todavia, isso não nos autoriza eliminar a natureza em nós. Nosso propósito é mostrar que é sempre a partir de nossa imanência na natureza que construimos nosso movimento de transcendência.

Recorremos aqui a Pico Della Mirandola (2015) que, em seu Discurso pela dignidade do homem, diz que Deus criou o ser humano constituído por um princípio de indeterminação. Na natureza, com exceção do ser humano, tudo é estabelecido de maneira fixa ou determinada. Somente o ser humano tem uma existência aberta. Essa situação gera angustia, que nos lança num horizonte do possível, mas também cria uma dignidade especial, pois pela indeterminação temos uma vida aberta, que exige responsabilidade e respeito. Isso mostra toda a força de transcendência presente nos humanos. Não desejamos aqui explorar as questões em torno de uma possível hierarquia de superioridade da vida humana em relação às outras formas de vida. Não pretendemos situar o debate da vida humana no cenário do criacionismo ou do 
evolucionismo, discussão que pode ser suscitada no texto de Pico Della Mirandola. Nosso propósito é destacar no livro a ideia de que a vida humana é marcada por um princípio de indeterminação, que nos lança para um mundo que se estabelece como horizonte aberto.

Seguindo estes passos apresentados até aqui, precisamos dizer qual o sentido que temos de filosofia para orientar nossas reflexões sobre espiritualidade, temática central do IV Colóquio Internacional de Estética e Existência, realizado em novembro de 2019, na cidade de João Pessoa.

Nos posicionar sobre o sentido de filosofia significa apontar o horizonte filosófico de nossas reflexões. Estamos cientes, como diz Merleau-Ponty (1991), que a filosofia não é um léxico em que encontraríamos as definições precisas de todo o vocabulário filosófico. Ao contrário, a filosofia é a atitude de interrogar e, por esta razão, não podemos nos contentar com as resposta elaboradas e fechadas. A filosofia pode, pela força da interrogação, elaborar um pensamento sempre aberto que tende ao infinito.

Tudo começa no corpo. Mas o corpo humano é biológico e cultural. Ele salta do reflexo de preensão para a elaboração do cumprimento por meio do aperto de mão. $\mathrm{O}$ reflexo é dado, mas o aperto de mão precisa ser criado. O reflexo é obra da natureza. $\mathrm{O}$ aperto de mão é da cultura. $\mathrm{O}$ reflexo é estrutura comum. O aperto de mão é plural, pois implica uma forma de cumprimento que varia de cultura para cultura.

Em algumas culturas, quando duas pessoas se encontram, elas dão um aperto de mão. Em outras, apenas um aceno com a mão ou com a cabeça é suficiente. Podemos ver um beijo ou dois beijos como forma de se cumprimentar. Pode não haver contato físico, as pessoas fazem apenas uma pequena reverência. É possível esfregar o nariz no nariz do outro. $\mathrm{O}$ cumprimento segue uma tradição e não regras naturais.

$\mathrm{O}$ corpo não é apenas um sistema mecânico de órgãos em funcionamento. Ele é um manancial de construção de atributos simbólicos. Compreendemos que essas construções fazem o corpo romper a barreira do natural, fazendo nascer um horizonte de transcendência. Nesse sentido, é possível considerar a possiblidade de uma experiência de transbordamento a partir do corpo, que se eleva a condição de humano pelo trabalho da cultura. $\mathrm{O}$ corpo é matéria sujeita às leis da natureza. Mas o corpo é também sensibilidade que se dirige para outros corpos pela experiência de sentir.

Identificamos no corpo a possibilidade de transcendência. Isso se dá pela sensibilidade que nos direciona para o encontro com o outro. Dois corpos se olham, se tocam, sentem seus cheiros. Eles podem conversar. Trocar palavras, experiências. O corpo, enquanto matéria extensa e vida biológica, está sujeito às leis da natureza. Mas, o corpo também é capaz de ultrapassar tal condição de existência e construir vínculos transcendentais.

Propomos considerar o tema da transcendência sem descartar o corpo e os sentidos. Temos como referência a compreensão do entrelaçamento entre natureza e cultura na filosofia de Merleau-Ponty (1992). Propomos destacar o papel da fala e da escuta nesse entrelaçamento para mostrar que o corpo poder ser considerado como o lugar de encontros. Desse modo, o corpo pode falar e escutar a si mesmo, mas também pode dividir com o outro um tempo de fala e de escuta. Ele é capaz de falar para si mesmo e para o outro e, ao mesmo tempo, escutar a si mesmo e o outro. O intercorpóreo, que é vivido pelo corpo enquanto capacidade de sentir algo e sentir a si mesmo, é também experienciado na fala e na escuta. Quando falamos, realizamos isso para nós mesmos e para outro. Do mesmo modo, quando escutamos, somos capazes de escutar a nós mesmo e ao outro. Logo, a reversibilidade do sentir é vivida na fala e na escuta. 


\section{ANGústia E PROSA}

Nossa humanidade se revela de maneira profunda na conversa. A comunicação carrega de maneira exemplar o sentido de transcendência. Quando conversamos nos dirigimos para outrem. Desenvolvemos a capacidade de estar em companhia de um outrem. Temos um desafio: como estabelecer uma conversa acolhedora, considerando os desafios de que a fala e a escuta são, muitas vezes, minimizadas em função de uma vida acelerada em que a serenidade da conversa foi quase aniquilada?

$\mathrm{O}$ estilo de vida sempre ativo sem descanso, que encontramos nas grandes cidades, se intensifica de maneira acentuada na sociedade contemporânea do século XXI. Han (2017) denomina esse estilo de vida como sociedade do cansaço. Estamos vivendo numa sociedade marcada pela performance e pelo desempenho. Temos em evidência só a positividade da ação e da imposição de se fazer cada vez mais. Falta a negatividade do descanso e do repouso. Nos transformamos em máquinas de desempenhos excessivos. Nos agitamos para cumprir inúmeras tarefas que deixa a vida em estado de esgotamento.

Han (2017) diz que o excesso de performance deixa o ser humano muito limitado no seu olhar e no seu falar. Uma cegueira e uma surdez invade a vida humana empobrecendo a sua fala e, consequentemente, sua escuta. Nossos gestos de aproximação e comunicação com os nossos semelhantes ficam ameaçados. A exigência de ser o melhor nos leva a um cansaço que nos silencia e nos impede de acolher o outro. A mão trabalhadora em demasia destrói a mão lúdica. A doação, o acolhimento e o cuidado são arruinados na sociedade do cansaço. O foco no nobreak nos deixa o tempo todo agitados e em plena atividade. Não há lugar para o pit stop ou para o Shabat. Precisamos de repouso e de serenidade para poder ver outros horizontes em nossas vidas, que foram encobertos pelo excesso de trabalho

Podemos recorrer aqui ao conto Angustia de Anton Tchekhov para ilustrar o desejo de falar de ser escutado, marcas indispensáveis dos seres humanos. O texto fala de Yona, um cocheiro que tinha perdido seu filho. Precisava compartilhar isso com alguém, mas ninguém se dispunha a escutá-lo. Um militar apressado contrata os serviços de Yona e de seu cavalo. Com muita dificuldade, Yona diz: "perdi um filho esta semana". O militar apenas pergunta: "de que foi que morreu?". Yona tenta dar continuidade a conversa, mas o militar se volta para sua pressa. Reclama e insiste que o cocheiro apresse o cavalo. Depois Yona recebe em sua charrete três jovens que pagam uma viagem bem abaixo do preço e fazem o percurso insultando uns aos outros. Yona ainda diz, depois de uma pausa: "Esta semana... assim, perdi o meu filho". A única fala de um dos jovens foi: "todos vamos morrer". O destino dos passageiros chega. Eles descem e a angustia continua a tomar conta da vida de Yona. Não adianta, ninguém lhes dá os ouvidos. Sua saída foi compartilhar seu sofrimento com seu rocim. Yona encontra no seu cavalo a esperança de continuar humano naquela sombria cidade fria em que não se conversa, apenas se repete rotinas apressadas sem a troca de falas e escutas.

Podemos ainda considerar uma experiência, vivida por mim, no meu cotidiano. Certa vez, sai cedo de casa e fui à padaria. Já estava com o saco de pão na fila para pagá-lo, quando se aproxima um homem de meia idade e começa a falar: "Minha vozinha morreu. Ela era muito cuidadosa. Só comia peixe. Mas ela morreu de câncer. Mas ela está bem. Ela está no céu com Jesus. Eu gosto tanto de pão de queijo. Mas não tenho dinheiro suficiente. Meu dinheiro é pouco. Vou para casa. Até”. Fiquei depois me questionando porque razão não paguei alguns pãezinhos de queijo para ele. Eu tinha dinheiro que podia fazer isso. Fui para casa e compartilhei com minha esposa e meu filho o que tinha ocorrido. Somente, emocionado em lágrimas, no transcorrer da 
narrativa, pude compreender que ofereci para ele algo muito especial: "minha escuta acolhedora". Isso é fundamental para animar as nossas vidas se fazendo humana pela troca da fala e da escuta. Tive a oportunidade de viver a experiência de ofertar meus ouvidos e acolher a fala do outro. Ofereci a oportunidade daquele homem falar e escutar a si mesmo. Desempenhei, de uma certa forma, o papel do cavalo, no contexto da história de Anton Tchekhov.

O destaque dado aqui é a posição de abertura para construir vínculos extraordinários. Estamos pontuando a questão do pôr-se a falar e escutar na presença do outro. O ser humano precisa desse movimento de se abrir para o outro, que caracteriza a transcendência pela fala a pela escuta. $\mathrm{O}$ caminho aberto pela linguagem nos traz um horizonte de transcendência. Minha existência precisa do suporte do outro. Quando faço silêncio para escutar o outro que fala, não estou apenas atento às ondas sonoras que invadem meu aparelho auricular. Entro em contato com um campo de sentido que se desdobra em várias possibilidades de interpretação. Escutando, eu faço saltos para diferentes mundos de sentidos. Não vejo um louco falando com um cavalo. Não vejo um louco delirando na padaria. Vejo vidas que se abrem cujo corpo se faz presença naquilo que aparece. Pela fala e pela escuta entramos em contato com a essência do humano que é a transcendência. No campo da linguagem somos livres para poder ser muito mais do que foi determinado pela natureza. A fonte de ser do ser humano é a linguagem que nos faz romper com as repetições e as cristalizações mecânicas das determinações naturais.

Nas minhas reflexões, soma-se ao conto literário e à cena do cotidiano um sonho, que apresento como possibilidade de se pensar o ser humano numa perspectiva transcendental ou espiritual, ou seja, livre e aberta.

Estava conduzindo um carro pela Av. Governador Argemiro de Figueiredo no Bessa em João Pessoa, antigo bairro que morávamos. Estávamos eu e Andréa no veículo. De repente, vejo um objeto estranho no caminho. Paro e vou ver o que seria aquilo e acabo tocando no objeto estranho. Imediatamente, vem um carro verde, que atravessa na frente do veículo que conduzia, para e me aplica uma multa. Tempos depois, a multa chega à minha casa com um valor de 5.400,00 reais. Estava escrita na multa que eu havia violando a câmera de uma lombada eletrônica.

Como resto diurno do sonho elaborado, eu e Andréa fomos para uma reunião budista no dia anterior. Ela está fazendo o mestrado em Ciências da Religião na Universidade Federal da Paraíba. O professor de uma das disciplinas havia proposto a realização de duas aulas de campo, que consiste em vivenciar duas práticas religiosas diferentes da dela. Fomos bem recebidos naquela reunião e nos foi explicado como seria a cerimônia naquele dia. Agradecemos e perguntamos se poderíamos fazer fotos. A pessoa que nos acolheu disse que sim. Todavia, não era permitido fazer fotografias do interior do santuário.

Estávamos interditados de fazer fotos do que era profundamente sagrado para eles. Tive a oportunidade de testemunhar, por meio dos mantras e do santuário aberto, um modo de viver o exercício espiritual de se dirigir para o transcendente. Destaco que esta cerimônia acontece no início e no fim da programação. Presenciamos atividades com músicas, palestras, entrevistas e danças. Eu me reconheci humano naquelas apresentações que realizava o trabalho da cultura. Aqui, essa experiência soma-se ao sonho como vivências de aproximação e de distanciamento, que precisamos considerar quando nos relacionamos com coisas e com pessoas.

Isso nos faz lembrar do filme o último Samurai, dirigido por Edward Zwick. Podemos ver o esforço de Katsumoto de permanecer um samurai leal ao imperador e, ao mesmo tempo, fiel as tradições japonesas. O capitão Nathan Algren, veterano da 
guerra civil américa, é contratado para ajudar a treinar o exército imperial japonês, juntamente com os seu ex-comandante, no transcorrer da era Meiji. Durante a batalha que os sodados do imperador foi derrotado pelos samurais, Nathan Algren é rendido e capturado por Katsumoto, que ficou impressionado pela sua bravura e disposição de lutar até a morte. Ele era digno do título de samurai. Na aldeia, o capitão americano reaprende a ver o mundo. Ele entra em contato com outras formas de se buscar a transcendência que ele nunca tinha visto antes. Foi preciso esta experiência para que o americano percebesse que a luta do samurai era para honrar a tradição japonesa contra a ameaça da ocidentalização desenfreada.

\section{TUDO COMEÇA NO CORPO}

O exercício da espiritualidade parte do corpo, dirigindo-se para além dele, mas sempre a partir dele. Esse dirigir-se para a transcendência se faz essencialmente pela fala e pela escuta. A conversa pode nos conduzir para cenários que não estão prontos. Eles precisam ser criados pelos seus interlocutores. A inventividade nos lança para a transcendência. Para exercitar a transcendência, necessitamos nos projetar na aventura da linguagem, que nos conduz a expressividade.

Recordamos, neste momento, daquilo que Heidegger (2003) diz em seu texto $A$ caminho da linguagem: "a fala se consuma, mas nunca se acaba". Ou aquilo que Merleau-Ponty (1992) diz na Fenomenologia da Percepção: "a fala falada nunca esgota a fala falante". No dizer, a fala aparece e se recolhe, pois ela está sempre pronta para se expressar e se continuar falante. Ela nunca se realiza plenamente. Dito de outra maneira, podemos evocar aqui a diferença entre o enunciado e a enunciação. De um lado temos elaborações ditas, produzidas e pronunciadas que anunciam algum conteúdo a ser compreendido, interpretado ou traduzido. Do outro, temos o não-dito, produções que não se revelam explicitamente, pois elas estão ao serviço do desejo que se esconde.

Segundo Dubois (1969), o enunciado diz respeito a estrutura significante do enunciado que se organiza de maneira acabada e fechada. A enunciação trata de evocar o sujeito que produz o ato de criação do enunciado. No enunciado, podemos buscar a compreensão do que se diz, fugindo das ambiguidades da discursividade de quem fala. $\mathrm{Na}$ enunciação encontramos os elementos da voz, da prosódia e da entonação daquele que fala. É no contexto de considerarmos as dimensões do enunciado e da enunciação que a linguagem ganha toda sua força de um ato de comunicação.

Somos devedores de Benveniste (1974) no que diz respeito ao estabelecimento do paradigma da enunciação, que permitiu nos descolarmos de uma leitura muito restrita dos enunciados da fala para entrarmos no rico e dinâmico universo do sujeito falante. Abrir o horizonte da conversação individual da língua, por meio do discurso, representa o fortalecimento de nossa compreensão da fala e da escuta como esferas fundamentais da vida humana em busca de transcendência.

A fala e a escuta nos proporciona o estabelecimento de encontros que podem romper a repetição e nos laçar no campo do extraordinário. Acolhemos aqui as elaborações de Zygouris (2002), em seu texto $O$ vínculo inédito. Segundo ela, os vínculos humanos são sustentados pelo alicerce da presença singular que promove o encontro entre dois corpos que se mantém singulares. Ela recorre as diferenças entre mapa e território para argumentar esta afirmação. Lendo o artigo Formas, substância e diferença de Gregory Bateson, a psicanalista é provocada a pensar sobre a célebre formulação de Alfred Korzybski que diz que "o mapa não é o território". O mapa diz respeito a um esquema que usamos para nos orientarmos e deslocarmos no território. $\mathrm{O}$ 
espaço, denominado de território, é o lugar estranho que nos desafia a entrarmos em contato. De posse dessa diferença, Zygouris (2002) diz que o espírito humana nunca funciona como um mapa. Ele é sempre movido pela complexidade.

Os vínculos humanos pela fala e pela escuta não podem ser reduzidos a traçados precisos de um mapa. Na dinâmica de nossos encontros podemos criar relações inéditas que rasgam os mapas e nos jogam em territórios desconhecidos. Reconhecemos as dificuldades de abrirmos mão de nossos mapas para nos arriscarmos e aventuramos em territórios desconhecidos. Tudo isso prepara o terreno para apresentarmos as considerações finais de nosso artigo.

\section{CONSIDERaÇões Finais}

$\mathrm{Na}$ intenção de elaborar algumas considerações finais para concluir nosso artigo, gostaríamos de apresentar duas reflexões que se apresentam a minha mente nesse momento. A primeira remete ao capítulo dez do livro de Atos dos apóstolos e a segunda diz respeito a uma frase dita por uma paciente em análise.

Da passagem do livro de Atos, destaco aqui o momento em que Pedro, hospedado na casa de Simão o curtidor, sobe para o terraço e vai orar. Ele orava e sentia fome. Nesse momento, lhe sobreveio uma visão. Ele viu o céu aberto e um objeto descendo, como se fosse, caindo sobre a terra. No lençol, Pedro via vários animais quadrúpedes que rastejavam sobre a terra e aves de rapina. Ele também ouviu uma voz que dizia: levanta-te Pedro, mata e come. Pedro diz que não, pois jamais iria comer algo profano e impuro. Pela segunda vez a voz lhe diz para não chamar de profano o que Deus purificou. Pedro, completamente perplexo, foi levado a refletir para interpretar a visão. Mas o Espírito lhe diz que dois homens estão procurando ele. Esses dois homens eram da parte de Cornélio, que recebeu uma visão de um anjo lhe orientando para procurar Pedro, que estava em Jope.

Poderíamos dizer que tanto Cornélio como Pedro estavam delirando, vendo imagens e ouvindo vozes estranhas. Mas podemos dizer que nessa história nascia um encontro extraordinário de dois homens que não podiam se encontrar, pois um era gentil e outro era judeu. Pedro teve que rever seus conceitos. Ele teve que ver o mundo de outra forma. Há nessa história um apelo para a transcendência. Uma abertura para o além de si. A atitude higiênica de Pedro sofreu um abalo. Animais impuros servem para mostrar que os gentios são considerados impuros pelo viés do preconceito de da intolerância. Pedro precisava rever os seus conceitos e seus valores rígidos, caso quisesse valorizar de verdade o amor que pregava.

A segunda coisa que nos veio à mente, foi um longo silêncio de uma paciente seguida da seguinte reflexão: "vejo esses quadros de janelas e portas na parede que me faz pensar que a nossa mente é como se fosse essas janelas e essas portas que precisam ser abertas". Logo em seguida dessa elaboração, falo: "é preciso metaforizar a vida, fazendo da mente janelas que se abrem para se ver paisagens que jamais foram vistas". Nesse sentido, se nos apegarmos ao imanente de maneira radical, perdemos de vistas a possibilidade de lançarmos nossos olhares para outros territórios. Sem essa abertura jamais iremos realizar falas e escutas inusitadas que nos abre para a transcendência. A fala e a escuta, que constituem a aprosa que nos leva ao movimento de transcendência, ganham uma mobilidade inesgotável, fazendo com que a fala nunca se esgote no dito ou no enunciado. Nesse contexto, a escuta sempre se renova tendo em vista que a fala tem sempre algo novo a dizer pelo simples desejo de se comunicar. 


\section{REFERÊNCIAS}

CAMINHA, Iraquitan de Oliveira. Corpo vivido e corpo pulsional: um diálogo entre MerleauPonty e Freud. In: Narrativas do corpo. BARROS, Neuma, CAMINHA, Iraquitan de Oliveira e DE ALMEIDA, Ronaldo Monte. João Pessoa: Editora do CCTA, 2016.

24 BENVENISTE, Émile. Structuralisme et linguistique. In : Problèmes de Linguistique Générale 2. Paris : Gallimard, 1974.

DUBOIS, Jean. Énoncé et énonciation. In: Langages, $4^{\circ}$ année, no 13, 1969, p. 100-110.

DURKHEIM, Émile. As forma elementares da vida religiosa. São Paulo: Paulus, 1989.

HAN, Byung-Chul. A sociedade do cansaço. Petrópolis: Vozes, 2017.

HARARI, Yuval Noah. Homo Deus: uma breve história do amanhã. São Paulo: Companhia das letras, 2016.

HEIDEGGER, Martin. A caminho da fala. Petrópolis: Vozes, 2003.

FREUD, Sigmund. O mal-estar na civilização. São Paulo: Companhia das Letras, 2010.

MERLEAU-PONTY, Maurice. Phénoménologie de la Perception. Paris: Gallimard, 1992.

MERLEAU-PONTY, Maurice. Le visible et l'invisible. Paris: Gallimard, 1991.

PICO, Giovanni. Discurso pela dignidade do homem. Ponto Alegre: Editora Fi, 2015. Disponível em http://www.editorafi.org. Consultado em 20/10/2019.

TCHEKHOV, Anton. Angústia. Disponível em: http://obviousmag.org/o_adiador/2016/angustiaum-conto-de-anton-tchekhov.html. Consultado em 20/10/2019.

ZYGOURIS, Radmila. O vínculo inédito. São Paulo: Escuta, 2002. 